\title{
Long-term slow slip events along the Nankai trough delayed by the 2016 Kumamoto earthquake, Japan
}

\author{
Shinzaburo Ozawa*, Ryouji Kawabata, Kensuke Kokado and Hiroshi Yarai
}

\begin{abstract}
The Global Navigation Satellite System network in Japan detected transient crustal deformation along the Nankai trough, Japan, from June 2018. Time-dependent inversion analysis shows that a long-term slow slip event in northern Hyuga-nada Sea along the Nankai trough, Japan, started in June 2018 and decayed in October 2018. From October 2018, a slip area appeared in the Bungo channel and expanded to northern Hyuga-nada Sea and southwest Shikoku at the time of the maximum slip rate. The slip area in the middle of the Bungo channel started to abate around May 2019, with the slip in neighboring areas nearly stopping in August 2019. The estimated rupture propagation is different from those in the past Bungo channel SSEs, in which rupture propagated southwestward from the Shikoku side to the Kyushu Island side at the time of the maximum slip rate. Furthermore, the rupture in northern Hyuga-nada Sea preceded the Bungo channel SSE and reappeared together with the Bungo channel SSE at the time of the 2018-2019 event, though the northern Hyuga-nada Sea SSE followed the 2009-2011 Bungo channel SSE. There is a possibility that the differences in the rupture propagation and recurrence interval from the past events are due to the 2016 Kumamoto earthquake. The adjacent locked area along the Nankai trough subduction zone is a well-known seismic gap and the 2018-2019 SSE changed the stress state in favor of the occurrence of nearby subduction earthquakes.
\end{abstract}

Keywords: Slow slip event, Hyuga-nada Sea, Bungo channel

\section{Introduction}

Geodetic networks such as the Global Navigation Satellite System (GNSS) have detected many slow slip events (SSEs) worldwide (e.g., Schwartz and Rokosky 2007). SSEs usually occur in the transient area between a locked area and an aseismically creeping area (e.g., Schwartz and Rokosky 2007). Many SSEs have approximate recurrence intervals such as $\sim 6$ years for the Bungo channel longterm SSE (Yoshioka et al. 2015), 14 months for the Cascadia SSE (Rogers and Dragert 2003), 3-4.5 years for the Guerrero SSE, Mexico (Graham et al. 2016), 20 months for the Costa Rica SSEs (Voss et al. 2017), 2-5 years for the Hikurangi SSEs, New Zealand (Wallace and Beaven 2010), and 8 years for the Alaska SSE (Fu and Freymueller

*Correspondence: ozawa-s96sa@mlit.go.jp

Geospatial Information Authority of Japan, Ibaraki 305-0811, Japan
2013). SSEs have a variety of durations. We call SSEs with durations over several months long-term SSEs and those with durations of several days short-term SSEs in this study. The mechanism behind the observed variation of SSEs still remains to be clarified. Furthermore, the relationship between large earthquakes and SSEs is unclear. Since some SSEs have triggered nearby large earthquakes (e.g., Ruiz et al. 2017), monitoring of SSEs is indispensable to assess the hazard potential of nearby seismogenic areas.

The area along Shikoku and Kyushu Islands, Japan, in the Nankai trough subduction zone has experienced long-term SSEs many times and is a good place to investigate the characteristics of long-term SSEs (e.g., Takagi et al. 2019). Furthermore, the Nankai trough subduction zone is a well-known seismic gap (e.g., Kumagai 1996), and it is important to investigate SSEs along the Nankai 
trough to estimate the slip budget and properties of the plate interface.

Figure 1 shows the tectonic setting in Kyushu and Shikoku along the Nankai trough, southwest Japan. The Philippine Sea plate subducts beneath the Amur plate from the Nankai trough at a rate of 6 to $7 \mathrm{~cm} /$ year (Kreemer et al. 2014). Because of the subduction of the Philippine Sea plate, large interplate earthquakes have repeatedly occurred off Shikoku with a recurrence interval of around 140 years (e.g., Kumagai 1996) and in Hyuganada Sea with a recurrence interval of 20-30 years (e.g., Shiono et al. 1980). In down-dip areas of a seismogenic zone, long-term SSEs repeatedly occur, with short-term slow slip events located in the down-dip extension of the long-term slow slip area (e.g., Obara 2002; Hirose and Obara 2005). Long-term slow slip areas are approximately segmented into western Shikoku, Bungo channel, northern Hyuga-nada Sea, and southern Hyuga-nada Sea in this region (see Fig. 1b). Western Shikoku SSEs have a recurrence interval of around 6 years and a duration of several months to 1 year (Takagi et al. 2016, 2019). Major Bungo channel SSEs occurred in 1996-1998, 2003-2004, and 2009-2011 with a duration of 6 months to 2 years (Hirose et al. 1999; Ozawa et al. 2001; Yoshioka et al. 2015; Takagi et al. 2019). Southern Hyuga-nada Sea SSEs and northern Hyuga-nada Sea SSEs have occurred independently or simultaneously (e.g., Ozawa 2017; Takagi et al. 2019). Northern Hyuga-nada Sea SSEs occurred in 1996-1997, 2002, 2008, 2014, and 2016 with a duration of around 6 months (Ozawa 2017; Takagi et al. 2019).

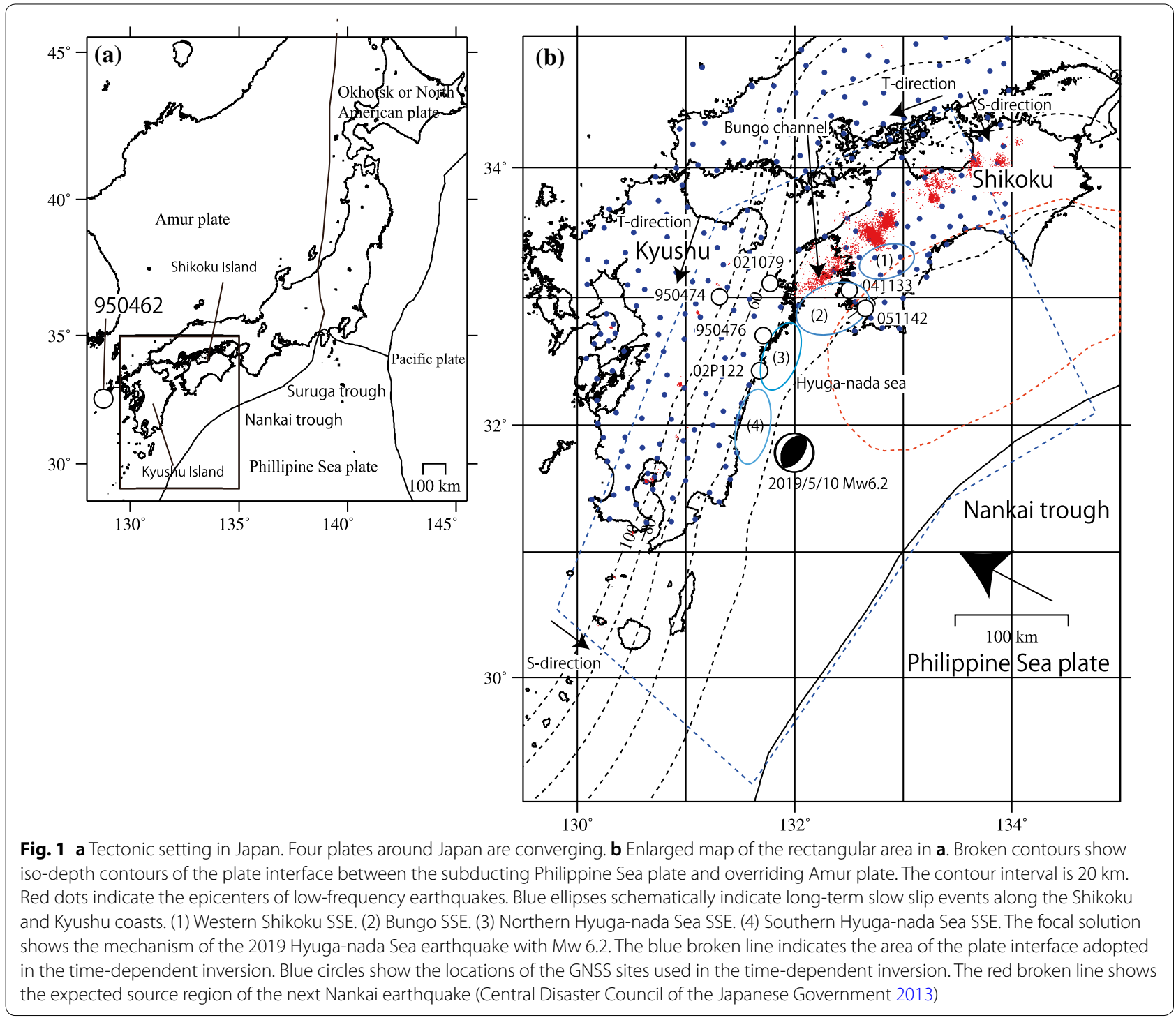


Southern Hyuga-nada Sea SSEs occur with a recurrence interval of 2 years and a duration of up to 1 year (e.g., Yarai and Ozawa 2013).

Before the 2016 Kumamoto earthquake sequence, long-term slow slip events were occurring in the Hyuganada Sea and southwestern Shikoku (Ozawa 2017) (Additional file 1: Figure S1). Since the Kumamoto earthquake, it has been unclear whether these SSEs have ceased or continued because of the large coseismic and postseismic crustal deformation due to the Kumamoto earthquake.

Two years after the Kumamoto earthquake, the GNSS network in Japan (GEONET) detected a transient from June 2018 along the Nankai trough subduction zone. The spatial pattern of this transient suggests the occurrence of a long-term SSE in the Nankai trough subduction zone. In this study, we investigate the spatio-temporal evolution of aseismic slip along the Nankai trough subduction zone from 2018 to 2019 on the basis of GNSS data. We compare the 2018-2019 event with the past major longterm SSEs in this area. We also discuss the possibility of stress perturbation caused by the 2016 Kumamoto earthquake affecting the long-term SSEs in 2018-2019.

\section{Analytical method}

GNSS data were analyzed using Bernese GPS software (version 5.0) on a daily basis with precise ephemeris and earth rotation parameters (Hatanaka et al. 2003). We transformed coordinates of longitudes, latitudes, and heights to east-west, north-south, and up-down components in a local framework, respectively. After this transformation, we removed annual components estimated for the period between 2000 and 2018 by regressing trigonometric and polynomial functions. We removed the linear trend for the period between January 1, 2017 and January 1, 2018 by regressing a linear function from the position time series without annual components.

The position time series show that the effect of the 2016 Kumamoto earthquake seems to have become steady after January 2017. Thus, we think that the above detrending is not significantly affected by the postseismic deformation following the Kumamoto earthquake. The adopted steady crustal deformation rate from January 2017 to January 2018 is shown in Additional file 1: Figure S2. In addition to the 2018-2019 SSE, we also analyzed the past major Bungo channel SSEs. In the past events, we adopted the linear trend from October 2007 to May 2009 in the detrending of position time series, when there was no transient.

We applied time-dependent inversion (McGuire and Segall 2003; Ozawa 2017) to the east-west, northsouth, and up-down components at 240 selected GPS sites (see Fig. 1b) for the period between January 1,
2017 and August, 1, 2019. We averaged the data over 3 -day windows and used the data every 3 days in timedependent inversion. We weighted horizontal and vertical components at a ratio of 5:1 in the following analysis, considering repeatability.

In the time-dependent inversion, we used a parametric spline surface to represent a fault interface as described in Ozawa et al. (2001). We adopted the geometric model of the Philippine Sea plate proposed by Hirose et al. (2008). The range of the adopted plate interface model is shown in Fig. 1b. The parametric spline surface is represented by two parameters, $\xi$ and $\eta$. The direction of increasing $\xi$ is named T-direction, and the direction of increasing $\eta$ is named S-direction as shown in Fig. 1b. In our representation of the spline surface, we took 35 grid knots in the T-direction and 15 grid knots in the S-direction in Fig. 1b. The spacing of the grid knot in the T-direction and S-direction is approximately $10 \mathrm{~km}$ and $20 \mathrm{~km}$, respectively. Green's function was calculated following Ozawa et al. (2001).

We adopted the following state $x(t)$ in the timedependent inversion:

$$
x(t)=\left(u_{1}, v_{1},-, u_{k}, v_{k},-, u_{L}, v_{L}, e_{\mathrm{EW}}, e_{\mathrm{NS}}, e_{\mathrm{ud}}\right),
$$

where $u_{k}$ indicates the slip and $v_{k}$ indicates the slip velocity at the $k$ th grid knot on the plate interface, which is represented by the spline surface of a total of $L$ grid knots. $e_{\mathrm{EW}}, e_{\mathrm{NS}}$, and $e_{\mathrm{UD}}$ indicate common mode errors in the position time series (Fukuda 2018). We incorporated spatial roughness in the transition equation as follows (Ozawa 2017):

$$
\begin{aligned}
& \lambda\left(M u_{n \mid n-1}-M u_{n-1 \mid n-1}\right) / \Delta t=e_{1}, \\
& \lambda M v_{n \mid n-1}=e_{2}
\end{aligned}
$$

where $M$ is the roughness matrix described in Ozawa et al. (2001) and $\lambda$ is the hyperparameter of spatial smoothing. $u_{n \mid n-1}$ and $u_{n-1 \mid n-1}$ are the predicted slip at time $n$ based on the data until time $n-1$ and the estimated slip at time $\mathrm{n}-1$ based on the data until time $n-1$, respectively. $\Delta t$ is the time lapse. $v_{n \mid n-1}$ is the predicted slip velocity at time $\mathrm{n}$ based on the data until time $n-1 . e_{1}$ and $e_{2}$ are Gaussian noise with 0 mean and a standard deviation of 1 .

We constrained the aseismic slip vector and slip velocity vector on the plate surface to within $10^{\circ}$ from the direction opposite to the motion of the Philippine Sea plate relative to the Amur plate using the method of Simon and Simon (2006). The direction of the Philippine sea plate relative to the Amur plate was taken from Kreemer et al. (2014). 
We conducted a checkerboard test by inverting the synthesized data with Gaussian errors with $1 \mathrm{~mm}$ standard deviation added for horizontal components and $5 \mathrm{~mm}$ standard deviation added for vertical components. The resolution near Shikoku and Kyushu in our inversion method is shown in Additional file 1: Figure S3, and the resolution is well resolved near Shikoku and Kyushu.

\section{Results and discussion}

Figure 2 shows the detrended position time series at selected stations. We can see a southeastward transient from June to October 2018 at sites 021079, 950474, and 950476. Southward displacements appear twice at 02P122 site from June to October 2018 and from February to March 2019. Site 950476 shows uplift from June to October 2018. From late 2018, we can see clear southeastward crustal deformation at all sites, which decays around July 2019. Sites 051142 and 041133 show uplift and sites 021079 and 950474 show subsidence between October 2018 and July 2019. Figure 3 shows the spatial pattern of detrended crustal deformation. A southeastward transient of up to $1 \mathrm{~cm}$ occurs in northern Kyushu Island between June and October 2018 (Fig. 3b, c). The spatial pattern of this crustal deformation strongly indicates the occurrence of long-term SSE in northern Hyuga-nada Sea. After this transient subsides, we can see slight southeastward transient crustal deformation from October to December 2018 in the Bungo channel area. A southeastward transient becomes clear between December 2018 and February 2019 in the Bungo channel area. We can see uplift in southwest Shikoku and subsidence in northern Kyushu for this period. The southeastward transient becomes large and expands to northern Kyushu and southwest Shikoku between February 2019 and April 2019, while southwest Shikoku shows uplift and northern Kyushu shows subsidence for this period. From April to June 2019, the horizontal transient in the Bungo channel becomes small and nearly disappears between June and August 2019. The observed transient is similar to the crustal deformation during the past Bungo channel longterm SSEs, indicating the occurrence of a Bungo channel long-term SSE from October 2018.

The time-dependent inversion shows the aseismic interplate slip between June and August 2018 in northern Hyuga-nada Sea (Fig. 4b). This area was experiencing long-term slow slip shortly before the 2016 Kumamoto earthquake (Additional file 1: Figure S1). No low-frequency earthquakes were observed in the area neighboring the estimated slow slip area. The aseismic slip area in northern Hyuga-nada Sea ended in October 2018 and the slip area moved to the Bungo channel from October 2018 (Fig. 4c, d). During this period, the number of low-frequency earthquakes increased in the down-dip extension of the long-term slow slip area in the Bungo channel. The magnitude of aseismic slip increased between December 2018 and February 2019. Low-frequency earthquakes continued to occur in the Bungo channel. The aseismic slip area propagated to Shikoku and to northern Hyuganada Sea with the slip magnitude increasing between February and April 2019. The slip rate is maximum for this period. The slip area in the middle of the Bungo channel abated between April and June 2019. The neighboring area decayed between June and August 2019. For this period, the number of low-frequency earthquakes decreased. The estimated moment magnitude between April 2018 and August 2019 was 7.0 with a rigidity of 30 GPa. The maximum slip was estimated to be approximately $30 \mathrm{~cm}$ in the Bungo channel area and $36 \mathrm{~cm}$ in northern Hyuga-nada Sea (see Table 1 and Additional file 1: Figure S4). The estimated magnitude and maximum slip in 2018-2019 are near the values for the past major Bungo channel SSEs (see Table 1).

In the last major Bungo channel long-term SSEs, the slip area moved southwestward at the time of the maximum slip rate (Yoshioka et al. 2015). Our inversion also shows southwestward rupture propagation at the time of the maximum slip rate for the past three events (Additional file 1: Figures S5-S7). Thus, the 2018 event shows different slip propagation in that the slip area expanded to southwest Shikoku and to northern Hyuga-nada Sea. Furthermore, in the 2009-2011 event, the northern Hyuga-nada Sea slip occurred after the Bungo channel slow slip, while the northern Hyuga-nada Sea SSE started before the Bungo channel SSE and reappeared again during the 2018-2019 event. Thus, the 2018-2019 rupture propagation is in contrast to that of the 2009-2010 event (Yoshioka et al. 2015) (Additional file 1: Figures S5-S7).

Long-term SSEs were occurring in northern Hyuganada Sea and southwestern Shikoku before the 2016 Kumamoto earthquake (Ozawa 2017). Additional file 1: Figure S8 shows $\triangle \mathrm{CFS}$ on the plate interface from the 2016 Kumamoto earthquake with a friction coefficient of 0.2 and slip direction opposite to the motion of the Philippine Sea plate. The fault parameters of the foreshock and main shocks are from Kobayashi et al. (2018). We can see a negative $\triangle C F S$ in northern Hyuga-nada Sea and the Bungo channel up to around $10 \mathrm{kPa}$. Takagi et al. (2019) estimated the average recurrence interval of the northern Hyuga-nada Sea SSEs to be 6 years. The latest events occurred in 2014 and 2016 separated by 2 years. Considering the average recurrence interval of 6 years, we consider that three events occurring in a series with a 2 year recurrence interval has a low probability. Furthermore, the northern Hyuga-nada Sea SSE occurred twice during the 2018-2019 event. In addition, the estimated maximum slip of $36 \mathrm{~cm}$ in northern 

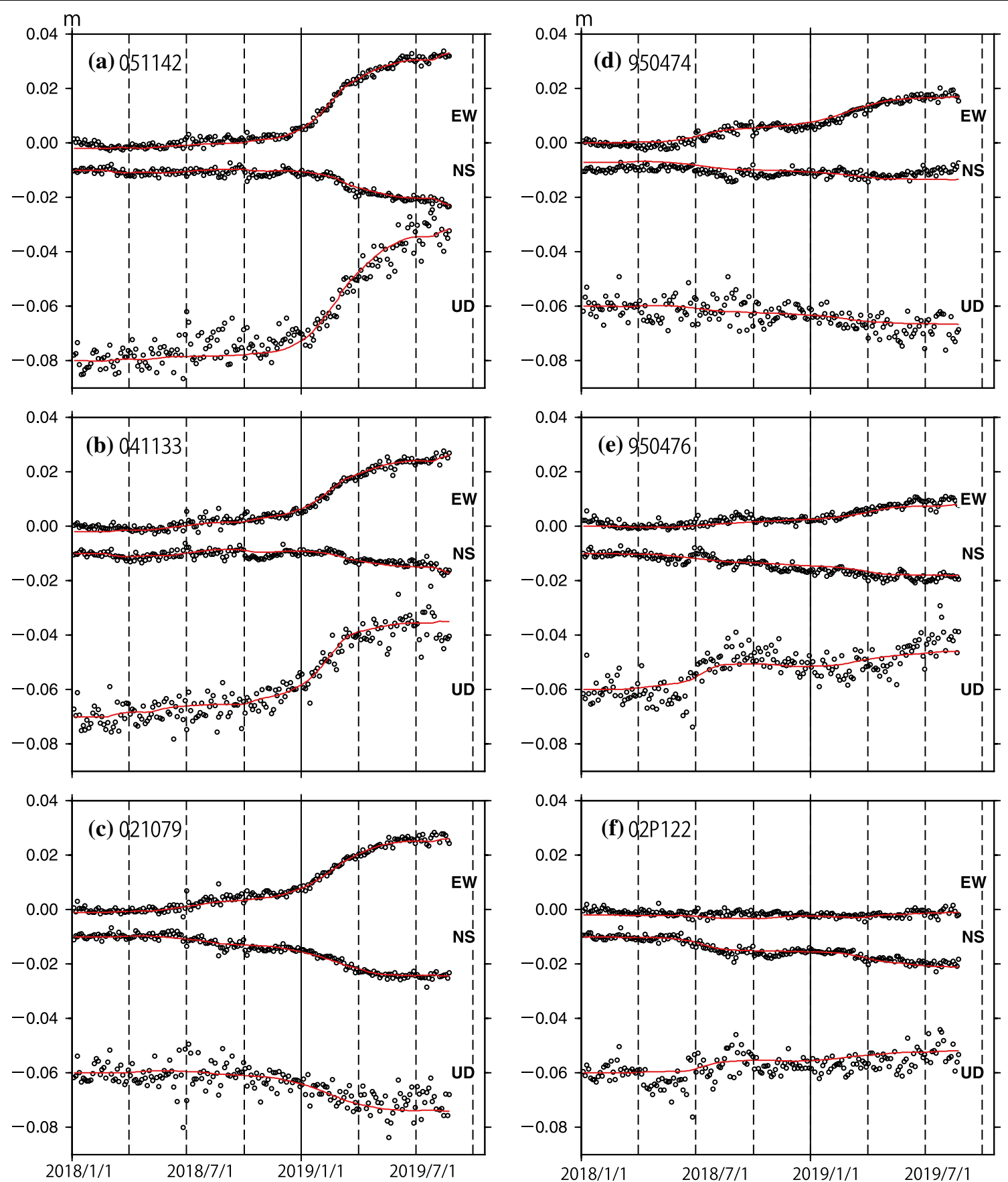

Fig. 2 Detrended position time series averaged over 3 days at selected GNSS sites relative to the 950462 site. The locations of these sites are shown in Fig. 1a, b. EW, NS, and UD indicate east-west, north-south, and up-down components with eastward, northward, and upward positive, respectively. Red lines show the computed transient from our optimal model. a 051142. b 041133. c 021079. d 950474. e 950476 . f 02 P 122

Hyuga-nada Sea is too large for the plate convergence to compensate, considering the 4 to $5 \mathrm{~cm}$ /year slip deficit rate in this area. This may indicate that the SSE in northern Hyuga-nada Sea which was occurring shortly before the Kumamoto earthquake did not release energy fully. We cannot rule out the possibility that the estimated sequence of the northern Hyuga-nada Sea SSE has been affected by the stress perturbation of the 2016 Kumamoto earthquake. Considering the negative $\triangle C F S$ in northern Hyuga-nada Sea, we hypothesize 


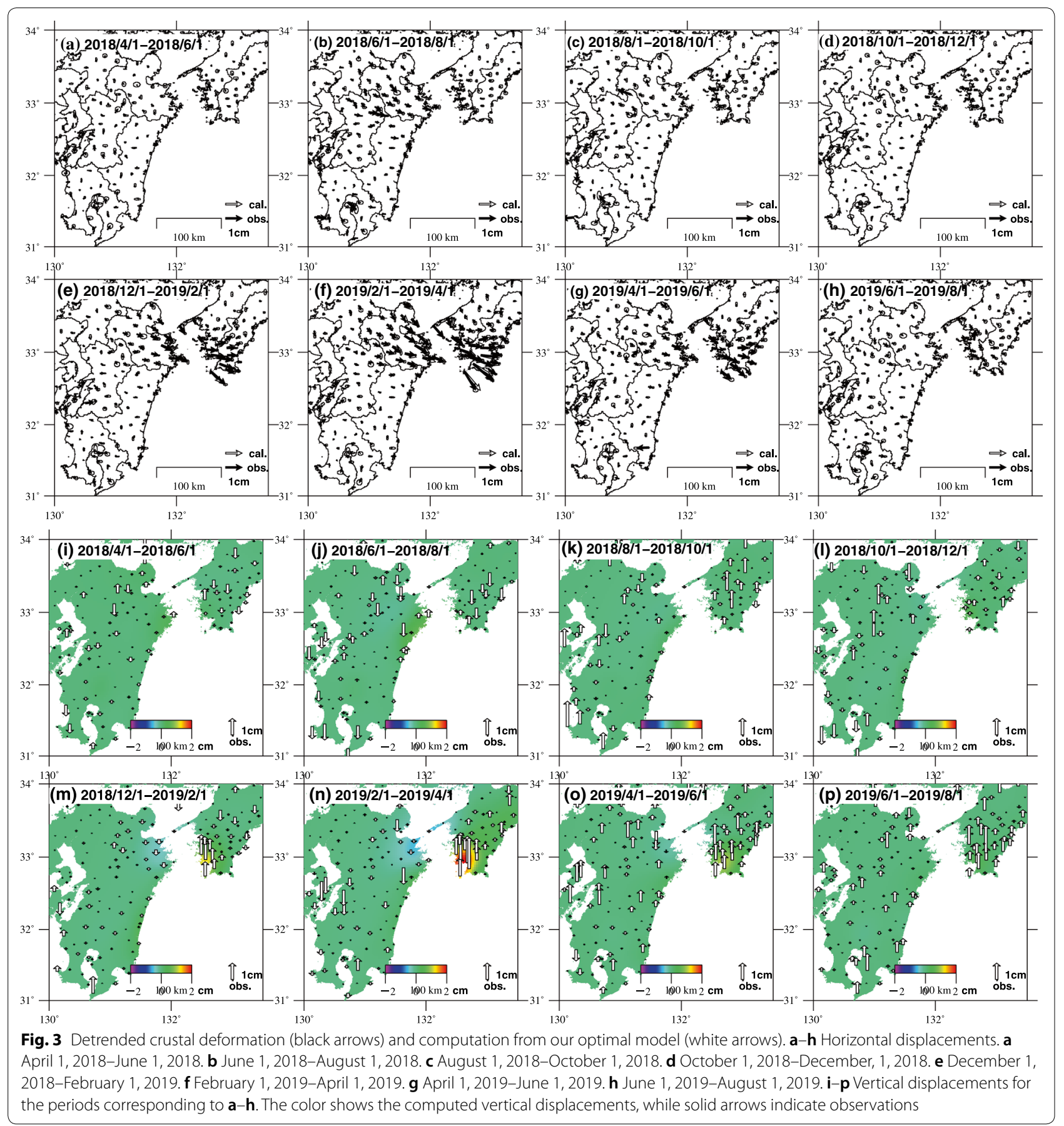

that the 2016 SSE ceased just after the Kumamoto earthquake and restarted 2 years later, which occurred twice during the 2018-2019 event. This hypothesis remains to be examined by observing the long-term SSE sequence in this area in the future. Based on the roughly estimated back slip model using two rectangular faults, $\triangle \mathrm{CFS}$ due to the plate convergence is estimated to be less than $100 \mathrm{kPa}$ in the maximum slip area in northern Hyuga-nada Sea and Bungo channel for 1 year (see Additional file 1: Figure S9). Stress drop of the SSE is roughly $100 \mathrm{kPa}$ assuming a typical length of $20 \mathrm{~km}$ and $30 \mathrm{~cm}$ slip with a rigidity of $30 \mathrm{GPa}$ (Eshelby 1957). The stress budget among the plate convergence, the Kumamoto earthquake, and stress drop of the SSE remain to be solved in a future study much more quantitatively in order to examine our hypothesis. 


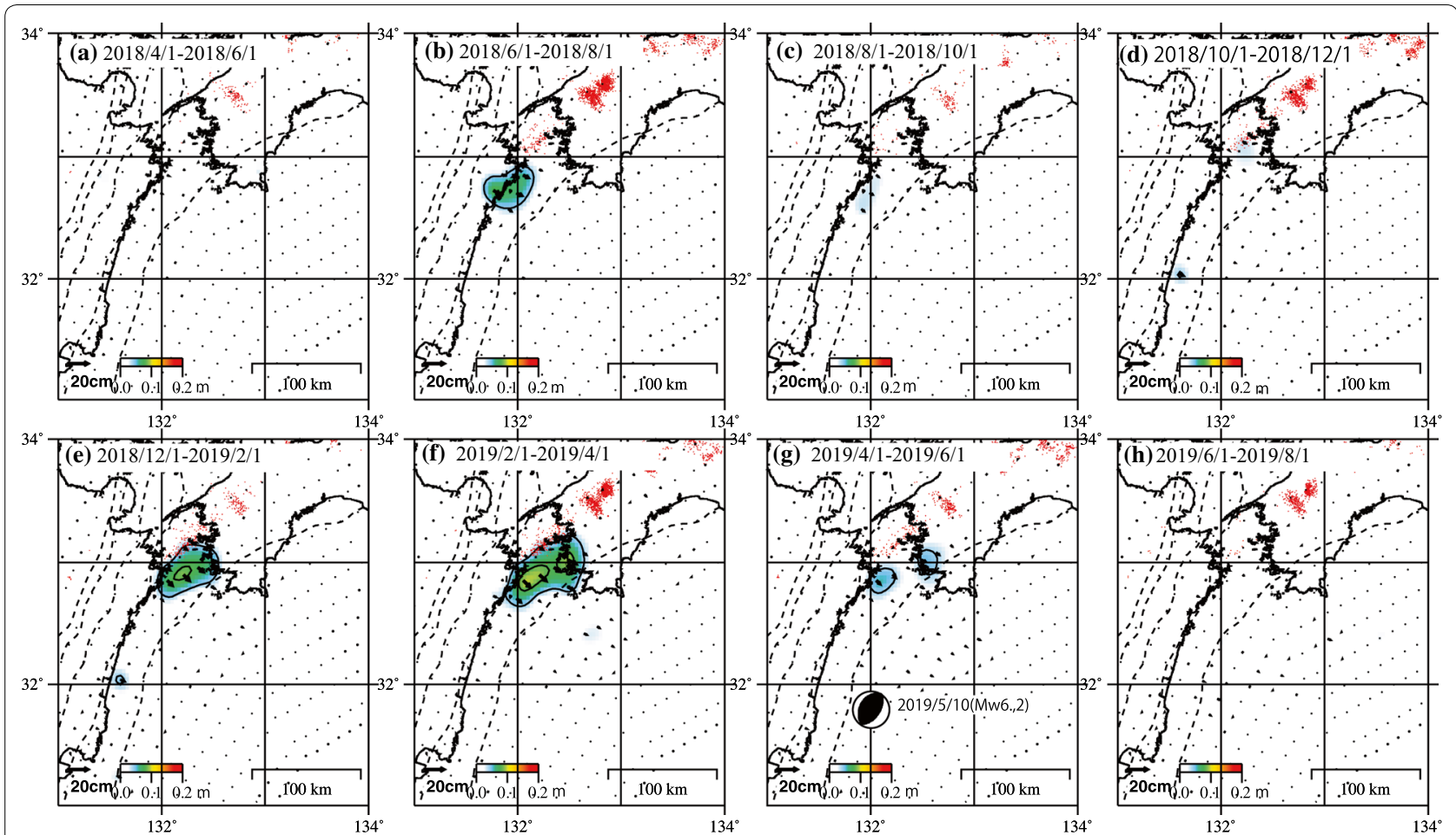

Fig. 4 Estimated interplate slip on the plate interface for the corresponding periods in Fig. 3. The color shows the magnitude of aseismic slip and solid arrows show the aseismic slip. The contour interval is $4 \mathrm{~cm}$. Broken contours indicate iso-depth contours of the plate interface between the subducting Philippine Sea plate and the overriding Amur plate with a contour interval of $20 \mathrm{~km}$. Red dots show the epicenters of low-frequency earthquakes for the corresponding period. The focal mechanism is shown at the epicenter of the Mw 6.2 Hyuga-nada earthquake on May 10, 2019 in g. a April 1, 2018-June 1, 2018. b June 1, 2018-August 1, 2018. c August 1, 2018-October 1, 2018. d October 1, 2018-December, 1, 2018. e December 1, 2018-February 1, 2019.f february 1, 2019-April 1, 2019. g April 1, 2019-June 1, 2019. h June 1, 2019-August 1, 2019

Table 1 The estimated moment, moment magnitude (Mw) and maximum slip for the past four major Bungo channel SSES

\begin{tabular}{llll}
\hline & Moment Nm & Mw & Maximum slip \\
\hline $2018 / 2 / 1-2019 / 8 / 1$ & $44\left(\times 10^{18}\right)$ & 7.0 & $\begin{array}{c}30 \mathrm{~cm}(36 \mathrm{~cm} \text { in } \\
\text { northern Hyuga- } \\
\text { nada })\end{array}$ \\
$2009 / 7 / 1-2011 / 3 / 1$ & $33\left(\times 10^{18}\right)$ & 6.9 & $31 \mathrm{~cm}$ \\
$2003 / 2 / 1-2004 / 2 / 1$ & $25\left(\times 10^{18}\right)$ & 6.8 & $37 \mathrm{~cm}$ \\
$1996 / 9 / 1-1998 / 7 / 1$ & $42\left(\times 10^{18}\right)$ & 7.0 & $33 \mathrm{~cm}$ \\
\hline
\end{tabular}

The slip in 2018-2019 in the same grid knot as those for the past SSEs is $30 \mathrm{~cm}$, although the maximum slip is $36 \mathrm{~cm}$ in the northern Hyuga-nada Sea grid knot. The 1996-1997 SSE does not include slip in southern Hyuga-nada Sea

The major Bungo channel SSEs detected by the GNSS network have an approximate recurrence interval of 5 to 6 years. The recurrence interval between the 20092011 event and the 2018-2019 event was approximately 7 years. Thus, there is a possibility that the 2018 event was delayed In fact, we expected a Bungo channel SSE in 2016, when southwest Shikoku started undergoing aseismic slip. We cannot rule out the possibility that this delay of 1 to 2 years may have been caused by the stress perturbation of the 2016 Kumamoto earthquake, which shows a negative $\triangle \mathrm{CFS}$ in the Bungo channel area.

Although no low-frequency earthquakes occurred at the time of the northern Hyuga-nada Sea SSE in 2018, there was an increase in the number of low-frequency earthquakes associated with the long-term Bungo channel SSE in the down-dip extension of the long-term slow slip area (see Fig. 4). This activation of low-frequency earthquakes associated with long-term slow slip events in the Bungo channel has also been observed in the previous Bungo channel long-term SSEs (e.g., Hirose and Obara 2005) (Additional file 1: Figure S10). We believe that this association is due to stress changes caused by long-term slow slip events, which show positive $\triangle \mathrm{CFS}$ in a low-frequency earthquake area (Additional file 1: Figure S11). Since the short-term SSEs that occurred in the study period accompanying low-frequency earthquakes were very small in magnitude, they do not affect the results of our analysis.

With regard to the slip budget on the plate interface, the slip deficit rate in the SSE area is around 4 to $5 \mathrm{~cm} /$ year (e.g., Yoshioka et al. 2015). The estimated aseismic 
slip in the Bungo channel reaches $30 \mathrm{~cm}$ (see Table 1 and Additional file 1: Figure S4). Thus, the slip deficit is being mostly released near the area with maximum slip, which is the western part of the slip area, although the eastern part of the slip area does not release all the accumulated slip budget of the slip deficit. This result is consistent with the conclusion by Yoshioka et al. (2015). Northern Hyuga-nada Sea SSEs occurred in 2002, 2005-2006, 2010-2011, 2014, and 2016 (Ozawa 2017; Takagi et al. 2019). Since the recurrence interval of northern Hyuganada Sea SSEs ranges from 2 to 5 years, the slip budget in the northern Hyuga-nada Sea SSEs remains unclear.

The effect of the 2018-2019 long-term SSE on the seismic gap shows an increase in $\triangle C F S$ of up to $10 \mathrm{kPa}$ in Hyuga-nada Sea and offshore of Shikoku (Additional file 1: Figure S11). Thus, the 2018-2019 SSE increased the potential of the expected Nankai earthquake, whose source area is schematically shown in Fig. 1b. Based on a simple back slip model, the $\triangle \mathrm{CFS}$ in the seismic gap is roughly $10 \mathrm{kPa}$ for 1 year and comparable to the effect of the SSE, although more detailed back slip modeling is necessary for further discussion (Additional file 1: Figure S9).

With regard to the Hyuga-nada area, a medium-size earthquake with Mw 6.2 occurred on May 10, 2019 in southern Hyuga-nada Sea. Figure 4d, e shows the aseismic slip in southern Hyuga-nada Sea in the down-dip extension of the 2019 Hyuga-nada earthquake before the earthquake. Although the magnitude of the estimated aseismic slip in southern Hyuga-nada Sea is very small, we cannot rule out the possibility that the aseismic slip in the down-dip extension preceded the May 10, 2019 earthquake. This hypothesis remains to be investigated in a future study.

\section{Conclusion}

Because the 2016 Kumamoto earthquake with Mw 7.6 changed the stress state on a plate interface, the 20182019 event is a good example of a long-term SSE affected by the stress perturbation of a large earthquake. We propose a hypothesis that the northern Hyuga-nada Sea SSE shortly before the 2016 Kumamoto earthquake ceased at the time of the earthquake and restarted 2 years later. We also suggest the possibility that the Bungo channel long-term SSE was delayed by the stress perturbation of the 2016 Kumamoto earthquake. The entire rupture propagation, which is different from those of the past Bungo channel area SSEs, may have also been caused by the perturbation of the 2016 Kumamoto earthquake. Further examination of our hypothesis is very important to understand the factors controlling the long-term SSE rupture sequence. Since a long-term SSE affects the stress state in a seismogenic zone, it is of great importance to monitor long-term SSEs. In fact, the 2018-2019 longterm SSE changed the stress state in favor of the expected Nankai earthquake at the bottom of the locked seismogenic zone. We propose the possibility that aseismic slip preceded the Mw 6.2 Hyuga-nada earthquake, which indicates the potential of assessing earthquake occurrence.

\section{Supplementary information}

Supplementary information accompanies this paper at https://doi. org/10.1186/s40623-020-01189-z.

Additional file 1: Figure S1. Aseismic slip on the plate interface from 2013 to 2016. Figure S2. Crustal deformation rate between January 2017 and January 2018. Figure S3. Checkerboard test. (A) Synthesized slip. (B) Inverted slip. Figure S4. Estimated aseismic interplate slip. Figure S5. Estimated aseismic interplate slip from 1996 to 1998. Gray arrows $<30$. Figure S6. Estimated aseismic interplate slip from 2003 to 2004. Gray arrows $<3 \sigma$. Figure S7. Estimated aseismic interplate slip from 2009 to 2011. Gray arrows $<3 \sigma$. Figure $\mathbf{S 8}$. $\triangle$ CFS on the plate interface for the 2016 Kumamoto earthquake. Figure S9. (A) Back slip model estimated by linearized least-squares inversion of the displacement rates for 2007 using two rectangular faults which are constrained to lie on the plate interface of the Philippine Sea plate. (B) $\triangle$ CFS on the rectangular faults in the direction opposite to the back slip for the model in (A). Green contours show the slip magnitude of the 2018-2019 long-term SSE. Figure S10. The number of low-frequency earthquakes and cumulative slip at the grid knot of the maximum slip in the Bungo channel. Figure S11. $\triangle$ CFS on the plate interface for the 2018-2019 long-term SSE with blue contours showing the slip magnitude of the SSE.

\section{Abbreviations}

GNSS: Global Navigation Satellite System; SSE: Slow slip event; $\triangle$ CFS: Coulomb failure stress change; Mw: Moment magnitude.

\section{Acknowledgements}

We are grateful to our colleagues for the helpful discussion. The low-frequency earthquake data are from Japan Meteorological Agency.

\section{Authors' contributions}

SO, HY, RK, and KK analyzed the data. SO wrote the manuscript. All authors read and approved the final manuscript.

\section{Funding}

This research is funded by the Geospatial Information Authority of Japan.

\section{Availability of data and materials}

The data used in this paper are available by contacting ozawa-s96sa@mlit. go.jp.

\section{Competing interests}

The authors declare that they have no competing interests.

Received: 28 February 2020 Accepted: 28 April 2020

Published online: 07 May 2020

\footnotetext{
References

Central Disaster Management Council of the Japanese Government (2013) Damage estimation of the Nankai earthquake (second report). Tokyo Cabinet Office, Government of Japan. http://ww.bousai.go.jp/jishin/ nankai/taisaku/pdf/1_1.pdf

Eshelby JD (1957) The determination of the elastic field of an ellipsoidal inclusion, and related problems. Proc R Soc Lond 241:376-396
} 
Fu Y, Freymueller JD (2013) Repeated large slow slip events at the southcentral Alaska subduction zone. Earth Planets Space 375:303-311. https://doi. org/10.1016/j.epsl.2013.05.049

Fukuda J (2018) Variability of the space-time evolution of slow slip events off the Boso peninsula, central Japan, from 1996 to 2014. J Geophys Res 123:732-760. https://doi.org/10.1002/2017JB014709

Graham S, DeMets C, Cabral-Cano E, Kostoglodov V, Rousset B, Walpersdorf A, Cotte N, Lasserre C, McCaffrey R, Salazar-Tlaczani L (2016) Slow slip history for the Mexico subduction zone: 2005 through 2011. Pure Appl Geophys 173(10-11):3445-3465

Hatanaka Y, lizuka T, Sawada M, Yamagiwa A, Kikuta Y, Johnson JM, Rocken C (2003) Improvement of the analysis strategy of GEONET. Bull Geogr Surv Inst 49:11-37

Hirose H, Obara K (2005) Repeating short-and long-term slow slip events with deep tremor activity around the Bungo channel region, southwest Japan. Earth Planets Space. https://doi.org/10.1186/BF03351875

Hirose H, Hirahara K, Kimata F, Fujii N, Miyazaki S (1999) A slow thrust slip event following the two 1996 Hyuga-nada earthquakes beneath the Bungo Channel, southwest Japan. Geophys Res Lett 26:3237-3240

Hirose F, Nakajima J, Hasegawa A (2008) Three-dimensional seismic velocity structure and configuration of the Philippine Sea slab in southwest Japan estimated by double-difference tomography. J Geophys Res 113:19782012. https://doi.org/10.1029/2007JB005274

Kobayashi T, Yarai H, Kawamaoto S, Morishita Y, Fujiwara S, Hiyama Y (2018) Crustal deformation and fault models of the 2016 Kumamoto earthquake sequence: foreshock and mainshock. In: Freymueller J, Sánchez L (eds) International symposium on advancing geodesy in a changing world. international association of geodesy symposia, vol 149. Springer, Cham, https://doi.org/10.1007/1345_2018_37

Kreemer C, Blewitt G, Klein EC (2014) A geodetic plate motion and global strain rate model. Geochem Geophys Geosys 15:3849-3889. https://doi. org/10.1002/2014/GC005407

Kumagai H (1996) Time sequence and tile recurrence model for large earthquakes along the Nankai trough revisited. Geophys Res Lett 23:1139-1142

McGuire JJ, Segall P (2003) Imaging of aseismic slip transients recorded by dense geodetic networks. Geophys J Int 155:778-788

Obara K (2002) Nonvolcanic deep tremor associated with subduction in southwest Japan. Science 296:1679. https://doi.org/10.1126/science.1070378

Ozawa S (2017) Long-term slow slip events along the Nankai trough subduction zone after the 2011 Tohoku earthquake in Japan. Earth Planets Space 69:56. https://doi.org/10.1186/s40623-017-0640-4

Ozawa S, Murakami M, Tada T (2001) Time-dependent inversion study of the slow thrust event in the Nankai trough subduction zone, southwest Japan. J Geophys Res 106:787-802
Rogers G, Dragert H (2003) Episodic tremor and slip on the Cascadia subduction zone: the chatter of silent slip. Science 300(5627):1942-1943. https:// doi.org/10.1126/science.1084783

Ruiz S, Aden-Antoniow F, Baez JC, Otarola C, Potin B, delCampo F, Poli P, Flores C, Satriano C, Leyton F, Madariaga R, Bernard P (2017) Nucleation phase and dynamic inversion of the Mw6.9 Valparaiso 2018 earthquake in central Chile. Geophys Res Lett 44:10290-10297. https://doi. org/10.1002/2017GL075675

Schwartz S, Rokosky JM (2007) Slow slip events and seismic tremor at circum-Pacific subduction zones. Rev Geophys 45:3004. https://doi. org/10.1029/2006rg000208

Shiono K, Mikumo T, Ishikawa Y (1980) Tectonics of the Kyushu-Ryukyu arc as evidenced from seismicity and focal mechanism of shallow to intermediate-depth earthquakes. J Phys Earth 28:17-43

Simon D, Simon DL (2006) Kalman filtering with inequality constraints for turbofan engine health estimation. IEE Proc Control Theory Appl 153:371-378

Takagi R, Obara K, Maeda T (2016) Slow slip event within a gap between tremor and locked zoned in the Nankai subduction zone. Geophys Res Lett 43:1066-1074. https://doi.org/10.1002/201GL060987

Takagi R, Uchida N, Obara K (2019) Along-strike variation and migration of long-term slow slip events in the western Nankai subduction zone, Japan. J Geophys Res. https://doi.org/10.1029/2018JB016738

Voss NK, Malservisi R, Dixon TH, Protti M (2017) Slow slip events in the early part of the earthquake cycle. J Geophys Res 122:6773-6786. https://doi. org/10.1002/2016JB013741

Wallace LM, Beavan J (2010) Diverse slow slip behavior at the Hikurangi subduction margin, New Zealand. J Geophys Res 115:B12402. https://doi. org/10.1029/2010JB007717

Yarai H, Ozawa S (2013) Quasi-periodic slow slip events in the afterslip area of the 1996 Hyuga-nada earthquakes, Japan. J Geophys Res 118:2512-2527. https://doi.org/10.1002/jgrb.50161

Yoshioka S, Matsuoka Y, Ide S (2015) Spatiotemporal slip distributions of three long-term slow slip events beneath the Bungo Channel, southwest Japan, inferred from inversion analyses of GPS data. Geophys J Int 201(3):1437-1455. https://doi.org/10.1093/gji/ggv022

\section{Publisher's Note}

Springer Nature remains neutral with regard to jurisdictional claims in published maps and institutional affiliations.

\section{Submit your manuscript to a SpringerOpen ${ }^{\circ}$ journal and benefit from:}

- Convenient online submission

- Rigorous peer review

- Open access: articles freely available online

- High visibility within the field

Retaining the copyright to your article

Submit your next manuscript at $\boldsymbol{\nabla}$ springeropen.com 